\title{
Solution Strategies of a Teacher Candidate: Rediscovering Numbers in Base Eight
}

Didem Akyüz

Middle East Technical University

\begin{abstract}
:
Up to today, many of the studies mostly investigated students' understanding of natural numbers rather than preservice teachers'. This study conducts a case study in order to investigate a preservice teacher's understanding of natural numbers and operations on them. The preservice teachers, who were enrolled in a senior year course in an elementary mathematics education department, used materials for natural numbers that aimed to teach the concepts and operations using base eight instead of customarily used base ten for a period. This way, preservice teachers had a chance to develop different strategies for the operations that they memorized in base ten and their thinking ways are investigated during the solution of operations. The results reveal that using different base supports preservice teachers to change their thinking style and interpret the problems from a different perspective without doing any memorization.
\end{abstract}

Keywords: natural numbers, prospective teachers, base 8, number operations

\section{İnönü University}

Journal of the Faculty of Education

Vol 17, No 2, 2016

pp. $199-216$

DOI: $10.17679 /$ iuefd. 17283573

\section{Suggested Citation}

Akyüz, D. (2016). Solution Strategies of a Teacher Candidate: Rediscovering Numbers in Base Eight, Inonu University Journal of the Faculty of Education, 17(2), 199-216. DOI: 10.17679/iuefd.17283573 


\section{EXTENDED ABSTRACT}

\section{Introduction}

Despite the importance of numbers for mathematics education, the number of studies that investigate teachers' understanding of natural numbers and operations on them are limited. Many studies point out a lack of understanding of the place-value concept (Zazkis \& Khoury, 1993; Ross, 2001) and lack of ability to recognize relationships between operations (Menon, 2004). It is important to delve into the nature of these misconceptions and understand their origins as they can shed light into common pitfalls experienced by students as well. However, understanding the nature and origins of these misconceptions is difficult using the base ten number system, as in this system, many operations are performed automatically by teachers without thinking about their meanings.

\section{Purpose}

To address this problem, this study aims to investigate a preservice teacher's understanding of natural numbers and operations within a classroom environment using a different number system. The teacher candidates, who were enrolled in a senior year course in an elementary mathematics education department, used materials for natural numbers that aimed to teach the concepts and operations using base eight instead of customarily used base ten for a period of 5 weeks. To this end, a course pack developed and used in earlier studies was adapted (Andreasen, 2006; Roy, 2008; Safi, 2009) into a senior level elementary mathematics education course in a large public university in Turkey. The course pack was entirely designed in base eight, which renders teacher candidates' past experience in base ten inapplicable for most cases. As such, they attempted to rediscover different operations. As they do this, the researcher investigated their misconceptions and development of the ideas.

\section{Method}

In order for the researcher to understand teacher candidates' development of ideas, it is important for them to share their reasoning both explicitly during classroom discussions and implicitly in their individual work (activities, worksheets, etc.). This requires a classroom environment where open discussions are encouraged. To this end, the current study was conducted in an inquiry-based classroom with established social norms (Cobb, 2001). This facilitated prospective teachers' participation into classroom discussions as freely sharing ideas and solution strategies were among the established social norms. As common in this kind of work, the transcribed classroom discussions are later analysed using Toulmin's model of argumentation. Although the classroom involved several students, in this study one student was taken as a case (pseudonym Meltem) and her solution strategies were investigated to a deeper extent. The motivation for the selection of this student was based on various solution strategies that she shared during classroom discussions and her individual activities. Furthermore, the selected student was one of the most active participants of classroom discussions and could elaborate her solution strategies. As such, the current work used case study as a qualitative research method.

\section{Findings}

It was observed that Meltem developed various strategies in solving integer problems and was able to connect different concepts to each other. This contributed to other teacher candidates' conceptual understanding as well. For example, it was observed that her usage of the open number line for developing various solutions and grouping strategies encouraged her peers to find different solution strategies. Furthermore, in solving questions Meltem attempted to make connections between different topics and strove to understand the other solutions proposed by her peers. When comparing the strategies and the overall behaviour exhibited by Meltem with those of the studies conducted abroad, similar features were observed (Roy, 2008: Safi, 2009).

\section{Discussion \& Conclusion}

It can be argued that instructing prospective teachers in base eight, as was done in the current study, can support a better understanding of natural numbers and natural number operations for teacher candidates. 
If the teacher candidates fail to develop various strategies for solving integer problems, the instructor can introduce these techniques to support their conceptual understanding. In particular, the solutions developed using open number line, the grouping mechanism such as candy boxes which can assist in addition and subtraction, and the concept of egg boxes which can contain eggs in different multiples can facilitate teacher candidates conceptual understanding of natural numbers and operations on them. The most important point that must be emphasized is that all of these techniques must be performed in a base different than base ten due to the familiarity of the teachers with this base. This gives teacher candidates an opportunity to develop strategies for performing various operations which are normally memorized for base ten. By using a different base, teacher candidates find themselves in the shoes of their prospective students and therefore can better relate to and prevent their future misconceptions. It also allows the researchers to tap into the thought process of teacher candidates and investigate their reasoning as they perform various operations with natural numbers. 


\title{
Bir Öğretmen Adayının Çözüm Stratejileri: Sayıları Sekizlik Tabanda Yeniden Keşfetme
}

\author{
Didem Akyüz \\ Orta Doğu Teknik Üniversitesi
}

Öz

Bugüne kadar yapılan çalışmalar çoğunlukla ögrrencilerin doğal sayıları nasıl anladıklarını incelemiş fakat ögretmen adaylarının doğal sayıları nasıl anladıkları ve ögrrettikleri üzerine yeterince yoğunlaşmamıştır. Bu çalışmada öğretmen adaylarının doğal sayılar kavramını ve doğal sayılardaki işlemleri nasıl anladığını araştırmak için bir durum çalışması yapılmıştır. Çalışmada ilköğretim matematik eğitimi bölümünde okuyan öğretmen adayları, 4. sınıf zorunlu ders kapsamında doğal sayılar ve doğal sayılar üzerindeki işlemleri onluk taban yerine sekizlik tabanda hazırlanan içerik ile işlemiştir. Böylece ögrretmen adaylarına onluk tabanda ezbere yaptığı birçok işlem için stratejiler geliştirme fırsatı verilmiş ve bu süreçte nasıl düşündükleri detaylı olarak araştırılmıştır. Araştırmanın sonucu farklı bir taban kullanmanın öğretmen adaylarının düşünce şeklini değiştirdiğini, ezberden çıkarak farklı bir bakış açısıyla soruları yorumladıklarını göstermektedir

Anahtar Kelimeler: doğal sayılar, öğretmen adayları, sekizlik taban, dört işlem

\section{İnönü Üniversitesi}

Eğitim Fakültesi Dergisi

Cilt 17, Sayı 2, 2016

ss. $199-216$

DOI: $10.17679 /$ iuefd. 17283573

\section{Önerilen Atıf}

Akyüz, D. (2016). Bir Öğretmen Adayının Çözüm Stratejileri: Sayıları Sekizlik Tabanda Yeniden Keşfetme. Inönü Üniversitesi Eğitim Fakültesi Dergisi, 17(2), 199-216. DOI: 10.17679/iuefd.17283573 


\section{GíRiş}

Doğal sayılar kavramı ve doğal sayılar üzerindeki işlemler ilkokul öğretim programının önemli bir kısmını oluşturmaktadır (MEB, 2015). Fakat çalışmalar birçok sınıf öğretmen adayının doğal sayılar konusunu öğretmek için farklı yaklaşımlara ve yeterli bilgi birikimine sahip olmadığını göstermektedir (Empson \& Junk, 2004; Hill, Ball, \& Schilling, 2008). Bunun en önemli sebeplerinden birinin de öğretmen adaylarının matematiğin anlayarak değil de kurallar dizisini takip ederek öğrenildiğine inanmalarıdır (Philipp ve ark., 2007).

Bir başka nedeni de öğretmen adaylarının sayı hissi stratejilerini kullanmada yaşadıkları zorluklardır (Yang \& Huang, 2004). Yang (2007) ve Tasao (2004) öğretmen adaylarının sayı hissinin düşük olduğunu ve bir çok öğretmen adayının sayılarla ilgili stratejilerde sadece algoritmaya bağlı kalarak problemleri çözdüklerini belirtmiştir. Sayı hissi kişilerin sayılar, işlemler ve bunlar arasındaki ilişkiler ile ilgili yeterli bilgiye sahip olup problem çözümlerinde bu bilgileri farklı durumlara uyarlamalarını içerir (Mclntosh, Reys, \& Reys, 1992). Sayı hissi gelişen kişiler sayılar ile ilgili işlemleri zihinden yapabilmekte, sayıların büyüklüğüne karar verebilmekte, farklı gösterimler arasında geçiş yapabilmekte ve problemlerin çözümünde çıkan sonuçların mantıksal bir cevap olup olmadığına karar verebilmektedirler (Markovits \& Sowder, 1994; Shumway, 2011). Bu nedenle doğal sayıların öğretiminde sayı hissi önemli bir yere sahiptir. Sayı hissi çoğu zaman içgüdüsel olarak ortaya çıkar ve somut materyal deneyimleri ile gelişir. Bu deneyimler geliştikçe sayı kavramı soyutlaşır (Kilpatrick, 2001).

Özellikle sınıf öğretmen adayları üzerinde yapılan çalışmalar öğretmen adaylarının doğal sayılar ile ilgili işlemleri yaparken farklı stratejiler kullanmada bilgi eksiklikleri olduğunu göstermiştir (McClain, 2003; Thanheiser, 2010). Öğretmen adaylarının çoğunun çok basamaklı saylarda işlemler yaparken geleneksel algoritmaları açıklamakta zorlandıkları ve bu algoritmalarda "tekrar gruplama" fikrini bilmedikleri ortaya çıkmıştır (Thanheiser, 2009, 2010). Sınıf öğretmen adaylarının işlemlerdeki algoritmaların anlamlarını açıklamakta ve öğrencilerin farklı bakış açılarını fark etmede çok zorlandıkları gözlemlenmiştir. Örneğin bir çarpma işleminde neden algoritmada bir basamak sola kayıldığını açıklayamamışlar ve kavram yanılgıları olan öğrencilerin çözümlerine bir anlam verememişlerdir. Benzer şekilde McClain (2003)'de öğretmen adaylarının doğal sayılar üzerinde toplama ve çıkarmada gruplama stratejilerini bilmediklerini fakat öğretmen adaylarından öğrenci bakış açısı ile düşünmeleri istendiğinde anlayarak öğrenmenin önemini keşfettiklerini ifade etmişlerdir.

Sadece algoritmalarda değil basamak değerini anlamada da sınıf öğretmen adaylarının \%80'ninin çok basamaklı bir sayıda sağdan sola gidildikçe her sayının kendisinden önceki sayının on katı olduğunu görmede zorluk çektikleri gözlemlenmiştir (Zazkis \& Khoury, 1993). Benzer şekilde Ross (2001)'de sınıf öğretmen adaylarının basamak değerine anlam vermede sıkıntılar yaşadıklarını ifade etmiştir. Örneğin 25 sayısı içindeki 2 ve 5 'in neyi temsil ettiği sorulduğunda öğretmenlerin 2'nin 20'yi ifade ettiğini görmede zorluklar yaşadıklarını vurgulamıştır. Ayrıca araştırmacılar sınıf öğretmen adaylarının ilişkisel düşünmede zorluk yaşadıklarını gözlemlemiştir (Menon, 2004). Örneğin öğretmen adaylarından önce 45+32 işleminin sonucunu bulmaları istenmiş daha sonra da 46+32 işlemi sorulmuştur. Birçok öğretmenin işlemi tekrardan algoritma ile çözdüğü gözlemlenmiştir. Bu da öğretmen adaylarının genel olarak matematiksel anlamalarının ve öğretimsel açıklamalarının çoğunlukla işlemsel olduğunu göstermektedir (Uçar, 2011).

Yapılan çalışmalar eğitimcilerin öğretmen adaylarının farklı çözüm stratejilerini keşfetmelerine yönelik onlara destek olmaları gerektiğini vurgulamaktadır (Tirosh, 2000). Öğretmen yetiştirme programlarında öğrencilerin yapabilecekleri ortak yanılgılar tartışılmalı ve öğretmen adaylarının bu çözümlere yatkınlıkları arttırılmalıdır (Ashlock, 2002). Diğer bir önemli nokta da öğretmen adaylarına onların öğretmelerini istediğimiz şekilde bir eğitim vermektir. Öğretmen adaylarının öğretecekleri herhangi bir konuda onları da zorlayacak sorular sormak ve onların bu konuda detaylı olarak düşünmelerini sağlamak eğitimcilerin önemli görevlerinden biri olmalıdır (Lerman, 2000).

Birçok öğretmen adayı kendilerinin bile üniversite seviyesinde, ilkokulda öğretilen temel konuların nedenini anlamakta zorlandıklarını bu nedenle de öğrencilerin bu konuları anlayarak öğrenmelerinin mümkün olmadığını düşünmektedir. Bu inanışlar öğretmen adaylarının matematiği etkili olarak öğretmelerini oldukça kısıtlamaktadır (Ball, Bass, ve Hill, 2004). Öğretmen adaylarının geleceğin öğretmenleri olduğu ve öğretmenlerin de öğrencinin bir konuyu anlamasında önemli bir etken olduğu düşünüldüğünde; öğretmen adaylarının doğal sayılar gibi temel bir konuyu anlayarak öğretmelerinin önemi ortaya çıkmaktadır (Ball, Bass, \& Hill, 2004; Hiebert \& Grouws, 2007).

Bunu başarabilmek için de öğretmen adaylarının doğal sayılarda işlemlerin sonucunu bulurken kullanılan farklı stratejileri kendilerinin keşfetmeleri gerekmektedir (Thanheiser, 2009). Maalesef birçok öğretmen 
adayının öğrencilerin doğal sayılarda yapmış oldukları hataları ve stratejileri tahmin etmede sıkıntı yaşadığı gözlemlenmiştir (Son, 2016a, 2016b).

Öğrencilerde onluk sistemde bunu başarmak çok daha kolaydır. Yapılan çalışmalarda öğrencilerden doğal sayılarda dört işlem yaparken kendi stratejilerini geliştirmeleri istendiğinde; öğrencilerin basamak değeri, tahmin etme, sayı hissi ve işlemlerin özellikleri arasındaki ilşkiyi arttırdıkları ortaya çıkmıştır (Huinker, Freckman, \& Steinmeyer, 2003; Selter, 2001). Öğretmen adaylarının onluk sisteme olan yatkınlıkları ve bu sistemdeki işlemleri artık düşünmeden hızlıca yapabilmeleri onların öğrenciler gibi farklı yolları keşfetmelerini zorlaştırmaktadır (Hopkins \& Cady, 2007). Bu nedenle çalışmalar öğretmen adayları ile çalışırken alternatif bir taban geliştirmenin ve bu taban üzerinde işlem yapmanın öğretmen adaylarını daha çok düşündüreceğini ve öğrencilerin işlemleri ve onluk sayı sistemini nasıl öğrendikleri hakkında daha iyi bir fikre sahip olacaklarını göstermiştir (Andreasen, 2006; Cady, Hopkins, \& Hodges, 2008; McClain, 2003; Thanheiser, 2009). Böylece öğretmen adayları öğrenciler gibi doğal sayıları ve doğal sayılarda yapılan işlemleri ilk defa öğreniyor olmasalar da; farklı tabanda yapılan işlemlere çok alışık olmadıkları için öğrenciler gibi farklı stratejiler geliştirme fırsatı bulacaklardır.

Bu çalışmanın amacına uygun olarak sekizlik taban seçilmiştir. Sekizlik tabanın seçilmesinin nedeni onluk taban gibi çift olması ve hemen maksimum değere ulaşılmamasıdır. Daha önce de belirtildiği gibi öğrencilerin aksine öğretmenler onluk tabanda çok fazla geçmiş deneyime sahiptirler. Sekizlik taban kullanılarak öğretmen adayları doğal sayılar ve doğal sayılar üzerindeki işlemleri tekrardan keşfetme ve değerlendirme şansına sahip olacaklardır. Sekizlik taban kullanarak öğretmenlerin kavramsal ve işlemsel düzeyde doğal sayıları nasıl anladıklarını araştıran çalışmalar öğretmen adaylarının çözümlerinin öğrencilerle benzerlikler gösterdiğini belirtmişlerdir (Andreasen, 2006; Roy, 2008; Safi, 2009). Bu çalışmada amaç bir öğretmen adayının sekizlik tabanda doğal sayılarda işlemleri yaparken nasıl düşündüğünü detaylı olarak araştırmaktır. Bu araştırmada sınıf ortamında öğretmen adaylarının öğrenmeleri onların bireysel olarak sınıf tartışmasına katılması ile gerçekleşmiştir. Bu da "gelişen perspektif (emergent perspective)" teorik çerçevesiyle açıklanabilir (Cobb \& Yackel, 1996). Bu çerçeveye göre, öğrenmenin hem bireysel hem de sosyal olmak üzere iki daldan eşit şekilde, biri diğerinden üstün olmadan gerçekleştiği varsayılmaktadır. Bu teorik çerçevede sosyal normlar sınıftaki herkes tarafından kabul edilen kuralları oluşturmaktadır. Örneğin, anlamadıkları bir durum olduğunda sorularını rahatça sorabilme, yanlış bir cevap vermekten çekinmeme ya da cevabına katılmadığı bir arkadaşı olduğunda bunu rahatça söylemeyi içermektedir. Sosyo-matematik normları ise soruların matematiksel olarak anlamlarını sorgulama, bir cevabın neden öyle olduğunu kendi kendine sorma, bir sorunun çözümünden yola çıkararak bir tahminde bulunma sonra da bunu ispat etme veya gerekçelendirme gibi durumları içermektedir. Bireysel perspektif ise kişinin kendisiyle doğrudan ilgilidir. Bu çalışmada, bu teorik çerçeveyi kullanarak seçilen katılımcının çözüm stratejileri, sınıf ortamından çözümlerinin nasıl etkilendiği ve kendi çözümlerinin de sınıf tartışmasına nasıl etki ettiği araştırılmıştır.

\section{YÖNTEM}

Bu çalışmada nitel araştırma yöntemlerinden biri olan durum çalışması uygulanarak, ilköğretim matematik öğretmen adaylarının doğal sayılar kavramı ve doğal sayılar üzerindeki işlemleri bireysel olarak nasıl anladığı sınıf ortamında araştırımıştır. Durum çalışması yapmanın amacı olayı derinlemesine incelemek ve kişilerin düşüncelerini ayrıntılı olarak araştırmaktır (Denzin \& Lincoln, 2000; Merriam, 1988). Durum çalışması olay ve günlük yaşam iç içe geçtiğinde ve içerik olaydan tam olarak ayrılmadığında uygulanır (Yin, 2003). Durum çalışmaları, özellikle kişilerin günlük hayat örneklerinin konuşulduğu sınıf ortamında konuyu nasıl anladıkları araştırılmak istendiğinde uygundur (Stake, 2006). Nitel araştırmaların temel amaçlarından biri anlamayı daha iyi sorgulamaktır (Creswell, 1998).

\section{Çalışma Grubu}

Bu araştırma Ankara'da yer alan bir devlet üniversitesinde gerçekleştirilmiştir. Ders sırasında öğretmen adayları daha önceden hazırlanmış olan ders paketindeki soruları önce okuyarak kendileri çözmüş daha sonra da sınıf ortamında beraberce tartışmışlardır. Çalışmanın öncesinde ve sonrasında öğretmen adaylarının bilgilerinin ölçülebilmesi amacıyla geçerlilik ve güvenilirliği test edilmiş olan "öğretmenler için alan bilgisi" adı altında geliştirilen ilkokul ve ortaokul öğrencilerinin matematiği anlaması için öğretmenlerin sahip olması gereken bilgiyi ölçen bir test uygulanmıştır (Ball \& Hill, 2008). Bu testte temel olarak iki bilgi türü ölçülmektedir: Matematik alan bilgisi ve öğretmenlik alan bilgisi. Burada matematik alan bilgisi ile ifade edilmek istenen, öğretmenlerin bir matematik sorusunu çözebilmek için kullandıkları hesaplama, doğru karar verme yeteneği ve problem çözme becerisini kapsayan bilgi türüdür. Öğretmenlik bilgisi ise öğretmenlerin 
bir matematik problemindeki farklı çözüm stratejileri hakkındaki bilgisi ile öğrencilerin yanılgılarını öngören bilgiyi içermektedir. Çalışmada bu testteki sorulardan sayılar ile ilgili olanlar alınmıştır. Değerlendirmede her soruya 1 puan verilmiştir. Bazı sorular alt sorular içerdiğinden toplamda, test 36 puan üzerinden değerlendirilmiştir.

Bu testin yapılmasının nedenlerinden biri öğretmen adaylarından hangisinde bilgi değişiminin en fazla olduğunu gözlemlemek, bir diğeri de uygulanan içeriğin öğretmen adaylarının bilgisini pozitif yönde arttırdığını dolayısıyla onların bilgisine katkıda bulunduğunu göstermektir. 23 öğretmen adayının ön-son test sonuçlarının istatistiksel değerleri verilmiştir (Tablo 1). Bağımlı örneklem t-testi yapmadan önce gerektirdiği varsayımlar kontrol edilmiştir. Normallik varsayımı kontrolünde çarpıklık katsayısı normallik sınırı içinde yer almış, histogram ve gövde yaprak diyagramı normal dağılıma benzer çıkmış ve Shapiro-Wilks testinin sonucu anlamlı çıkmamıştır. Yapılan bağımlı örneklem t testi sonucunda öğrencilerin ön son testleri $(M=24, S . D=7.6)$ ve son testleri $(M=26.4, S . D=10.1)$ arasında $t(22)=-2.384, p=0.026(\alpha=0,05)$ istatiksel olarak önemli bir fark bulunmuştur. Buradan da içeriğin öğretmen adaylarının bilgisine olumlu yönde geliştirdiğini söyleyebiliriz.

Tablo 1

Ders öncesi ve sonrası t testi sonuçları

\begin{tabular}{|r|r|r|r|c|}
\hline & \multicolumn{1}{|c}{ Paired Samples Statistics } \\
\hline & \multicolumn{1}{|c|}{ Mean } & N & Std. Deviation & $\begin{array}{c}\text { Std. Error } \\
\text { Mean }\end{array}$ \\
\hline Pair 1 pre & 24.0435 & 23 & 7.66621 & 1.59851 \\
Dost & 26.3783 & 23 & 10.15350 & 2.11715 \\
\hline
\end{tabular}

Paired Samples Test

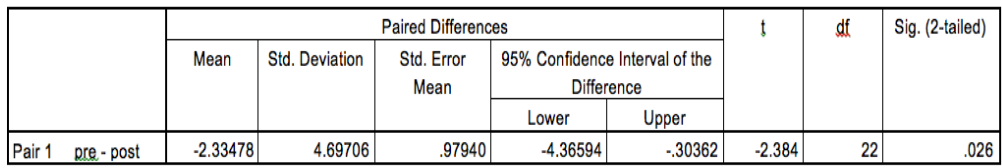

Çalışmada amaçlı örnekleme kullanılmıştır. Amaçlı örnekleme çalışmada derinleme inceleme yapabilmek için seçilir. Burada amaç genelleme yapabilmek değil, olayı derinlemesine inceleyebilmektir (Maxwell, 1996). Çalışmada dördüncü sınıf ilköğretim matematik öğretmenliğinde okuyan yaş ortalaması 21 olan öğrencilerden bir kız öğrencinin görüşleri ayrıntılı olarak incelenmiştir. Bu öğretmen adayı ve dördüncü sınıf öğrencilerinin hepsi zorunlu ders olarak uygulanan matematik eğitimi içerikli dersi almıştır. Bunun yanı sıra öğretmen adayı daha önceden temel matematik, analiz, lineer cebir ve matematik eğitimi dersi olan metot dersini almıştır. Ayrıca bu öğretmen adayı okul deneyimi dersinde okullarda gözlem yapma fırsatı bulmuştur. Çalışmada seçilen öğretmen adayı hem ön testte yüksek bir performans göstermiş (36 puan üstünden 29 almıştır) hem de çalışma sonrasında bu performansını daha da arttırmıştır (36 puan üstünden 34 puan almıştır). Bu nedenle katılımcı olarak seçilmiştir. Bu öğretmen adayının seçilmesinin başka bir nedeni de başarılı bir öğrenci olması (toplam mezuniyet ortalaması: 3.5 üzerinde), çözümleri ayrıntılı olarak açıklayabilmesi ve farklı çözüm stratejilerinden örnekler sunabilmesidir.

\section{Dersin İçeriği}

Bu çalışmada kullanılan ders paketi ders içeriği geliştirme alanında deneyimli bir öğretim elemanı tarafından tasarlanmış ve deney tasarımlı bir ortamda birçok araştırmacı tarafından test edilmiştir (Andreasen, 2006; Roy, 2008; Safi, 2009). Ders paketinde yer alan etkinlikler bu bölümde kısaca özetlenecektir.

Derse sekizlik taban öğrencilere tanıtılarak başlanmış ve aşağıdaki tablo öğrenciler tarafından doldurulmuştur. Burada önemli olan nokta 7'den sonra gelen 10 rakamı "on" değil "bir-ve-sıfır", 20 rakamı "yirmi" değil "iki-ve-sıfır" olarak isimlendirilmiştir. 


\begin{tabular}{|c|c|c|c|c|c|c|c|}
\hline 0 & 1 & 2 & 3 & 4 & 5 & 6 & 7 \\
\hline 10 & 11 & 12 & 13 & 14 & 15 & 16 & 17 \\
\hline 20 & 21 & 22 & 23 & 24 & 25 & 26 & 27 \\
\hline 30 & 31 & 32 & 33 & 34 & 35 & 36 & 37 \\
\hline 40 & 41 & 42 & 43 & 44 & 45 & 46 & 47 \\
\hline 50 & 51 & 52 & 53 & 54 & 55 & 56 & 57 \\
\hline 60 & 61 & 62 & 63 & 64 & 65 & 66 & 67 \\
\hline 70 & 71 & 72 & 73 & 74 & 75 & 76 & 77 \\
\hline
\end{tabular}

Şekil 1. Sekizlik tabanda en çok iki basamaklı sayılar tablosu

Zaman ilerledikçe öğretim elemanı öğrencilerden tabloyu da kullanarak ikişerli, üçerli, dörderli, beşerli saymalarını istemiştir. Bu sırada öğretmen adaylarının sekizlik tabandaki kriterleri görmeleri hedeflenmiştir. Örneğin, onluk sistemde 40 yerine, sekizlik sistemde 50 geldiği görülmüştür Daha sonra öğretmen adaylarından "ikili sekizlik çerçeve" kullanarak soruları zihinden çözmeleri istenmiştir.

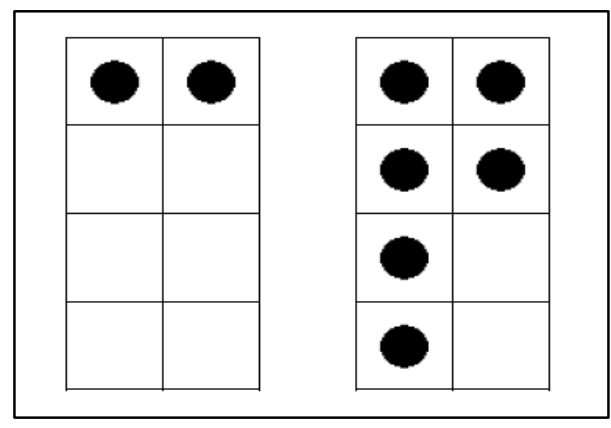

Şekil 2. İili sekizlik çerçeve

Ders paketindeki soruların içeriği "şekerci dükkanı ve şekerler" üzerine kurgulanmaktadır. Bunun amacı öğretmen adaylarının kafasında bir görsel imaj yaratarak onların günlük hayatla ilişki kurmalarına yardımcı olmak ve matematiksel fikirleri keşfetmelerini sağlamaktır. Örneğin sorularda kutu, şerit ve tane ilişkileri kullanılmıştır (Şekil 3). Her kutu 100 şeker tanesini, her şerit de 10 şeker tanesini kapsamaktadır (Cobb \& Wheatley, 1988). Bu içerik tanıtıldıktan sonra öncelikle öğrencilerin verilen rakamı farklı şekilde kutu, şerit ve tane kullanarak ifade etmeleri istenmiş daha sonra da toplama işlemi tanıtılmıştır.

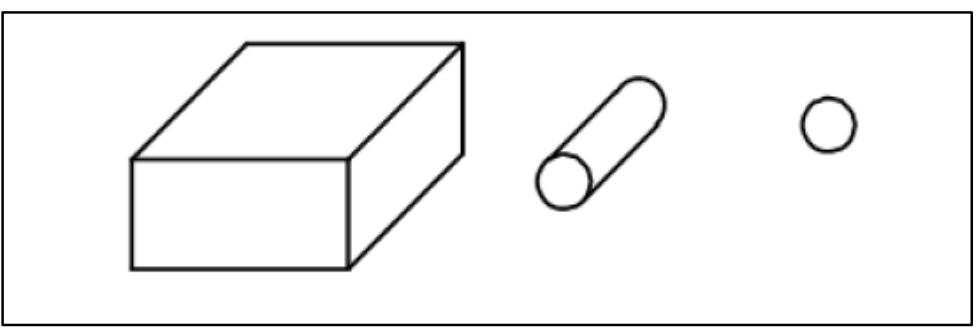

Şekil 3. Kutu, şerit ve tane gösterimleri

$\mathrm{Bu}$ fikirden yola çıkarak öğrencilerin toplama ve çıkarma işlemlerini yaparken birleştirme ve ayrıştırma kavramlarını kullanmaları hedeflenmiştir. Örneğin, "yeterli miktarda birlik yoksa bir şerit ayrıştırılarak 10 tane şeker elde edilebilir" ifadeleri kullanılmıştır. Daha sonra bu ifadeler biraz daha sade olması için K(kutu), Ş(şerit), T(tane) olarak Şekil 4'deki gibi ifade edilmiştir. 


\begin{tabular}{|l|l|l|}
\hline Kutular & Şeritler & Taneler \\
\hline 2 & 3 & 1 \\
\hline
\end{tabular}

Şekil 4. Sayıların kutu, şerit ve tane ile gösterimi

Öğretmen adayları benzer şekilde toplama ve çıkarma sorularını çözerken şeker dükkanı içeriğini kullanarak bunu yukarıdaki gibi ifade etmişler ve algoritmaları bu içerik üzerinden gerçekleştirmişlerdir. Çarpmaya geçildiğinde ise makinenin bozulduğu ve her bir şeritte 10 yerine farklı sayılar paketlendiği belirtilmiştir. Örneğin 6, 7, 12 ve 22 sayıları kullanarak onların çarpma stratejileri geliştirmeleri hedeflenmiştir. Daha sonra ise yumurta kutusu senaryosu kullanılmıştır. Örneğin "Bir şirket yumurta kutularını farklı şekilde üretiyor, 5'e 3'lük (veya 6'ya 12'lik) bir kutuya kaç yumurta yerleşir?" gibi sorular sorulmuştur. En sonunda ise öğretmen adayları farklı bölme soruları çözmüşlerdir. Bölme için özel bir içerik kullanılmamıştır. Burada belirtilmesi gereken önemli bir nokta ilk işlemler tanıtılırken yani toplama, çıkarma, çarpma ve bölme işlemlerinde şeker dükkanı içeriğinin kullanılmasının nedeni öğrencilerin doğal sayı işlemlerini yaparken kullanabilecekleri bir imajı desteklemektir.

\section{Veri Toplama Araçları}

Nitel bir çalışmada sorulara detaylı olarak cevap verebilmek için birçok kaynak arasında karşılaştırma yapmak önemlidir (Merriam, 1998). Bu nedenle, farklı kaynaklardan veri toplamak araştırmacı için önemlidir. Bu çalışma sırasında ders boyunca video kaydı yapılarak öğrencilerin çözümleri kaydedilmiştir. Bunun dışında öğrencilerin yapmış olduğu ödevlerin ve sınavların da fotokopisi alınarak bireysel çözümleri detaylı olarak incelenmiştir. Ayrıca araştırmacı derste önemli gördüğü noktaları da not almıştır.

\section{Verilerin Analizi}

Verilerin analizi sırasında matematik öğreniminde sıkça kullanılan Krummerheuer (1995)'in Toulmin (1969) tartışma (argumentation) modelinden uyarlayarak geliştirdiği analiz yöntemi kullanılmıştır. Toulmin (1969) modelinin dört önemli ana bileşeni vardır. Bunlardan iddia, araştırılan problemin sonucu olarak ifade edilebilir. Veri, bu iddiayı savunmak için öne sürülen bilgilerdir. Gerekçe, sunulan veriyi açıklamak için kullanılır; veriler ve iddialar arasındaki ilişkiyi gösterir. Gerekirse destekleyici ifadelerle gerekçelerin haklılığı gösterilir.

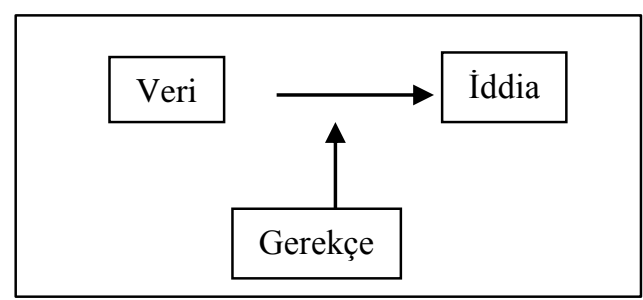

Şekil 5. Krummheuer tartışma şeması

Toulmin ile Krummheuer arasındaki temel fark Krummheuer'in tartışma modelininin temelini dört aşamadan değil de üç aşamadan oluştuğunu belirtmesidir (Şekil 5). Buna göre destekleyici tartışmanın temel modeli içinde yer almaz. Bunun en önemli sebebi de kişilerin düşüncelerinin bireysel olması ve bir kişinin diğerini desteklerken aynı cevabı desteklese de tam olarak onunla aynı stratejiyi kullanarak o sonuca erişip erişmediğinin dışardan gözlemlenememesidir. Bu nedenle Krummheuer başkası tarafından aynı tartışma için bulunan katkıyı yeni bir veri olarak yorumlamaktadır.

Bu çalışmada da data analiz edilirken Krummheuer tarafından önerilen tartışma için temel eleman olan veri, iddia ve gerekçe aşamaları kullanılmıştır. Örneğin, öğrencilere 25- (-10) işleminin sonucunun sorulduğunu varsayalım. Bu tartışma sırasında Ali, sonucun 35 olduğunu söyleyen bir iddiada bulunabilir. Öğretmen Ali'ye sonucu nasıl bulduğunu sorduğunda Ali "Sadece 25'e 10 ekledim" diye cevap verebilir. Krummheuer modeline göre Ali 35 cevabını vererek bir iddia'da bulunmuştur ve veri ile de nasıl bu sonucu elde ettiğini söylemiştir. Eğer Ali'den öğretmeni ya da arkadaşları daha çok açıklama isterse Ali şu şekilde açıklamasında gerekçe'yi de kapsayabilir: "25 TL'lik net varlığım vardı, 10 TL'lik borcumu kaldırdım, net varlığım 35 TL'ye yükseldi" şeklinde açıklama yapabilir (Stephan \& Akyuz, 2012). 
Krummheuer (2007) tartışmadaki aşamaların yanı sıra tartışmaya katılan kişinin konuşmasının içeriğini dört aşamaya ayırmıştır. Bu aşamalara göre kişi tartışmaya kendi düşünceleriyle başlıyorsa author olarak; söyleneni hiç değiştirmeden tekrarlıyor ise relayer olarak; söylenenden yola çıkarak kendi fikirlerini açıklıyorsa ghostee olarak ve söylenen ifadeyi farklı kelimelerle tekrar ediyorsa spokesman olarak adlandırmıştır ${ }^{1}$. Bu ifadelerin açıklamalarından da anlaşılabileceği gibi author ve ghostee tartışmanın içeriğinde sorumluluk alırken relayer ve sposkesman ifadelerin yeniden yapılandırılmasında yer alırlar (Krummheuer, 2007, 2015). Bu çalışmada toplanan veri sadece ifadelerin tartışmadaki fonksiyonuna (veri, gerekçe, sonuç) göre değil; kişilerin tartışmadaki fonksiyonunu (author, relayer, ghostee, spokesman) da inceleyerek analiz edilmiştir.

\section{BULGULAR}

\section{Toplama ve Çıkartma}

İlk hafta öğrencilere verilen sorulardan birisinde öğrencilerden 314-145 işlemini yapmaları istenmiştir. Birçok öğrenci farklı stratejiler geliştirmiştir. Öğretim elemanı tarafından cevaplar sorulduğunda öğrencilerden 166, 146 ve 147 gibi cevaplar gelmiştir. Daha sonra öğrencilerden farklı cevaplar verenler işlem hatası yaptıklarını söyleyerek cevabın 147 olduğunu belirtmiştir. Bunlardan birisi olan Meltem açık sayı doğrusunu kullanarak soruyu çözmeyi tercih etmiştir (Şekil 6). Sınıf ortamında öğrencinin çözümünü yaparken geçen diyalog aşağıdaki gibidir:

Ö: Nasıl bir çözüm yolu kullandın?

M: Önce 200 gittim, daha sonra 30 geri geldim, kolay olduğu için sonra 1 daha gittim. 200'den de 31'i çıkarınca cevabı buldum (gerekçe).

Ö: Cevap kaç?

M: Cevabı 147 çıkıyor (iddia).

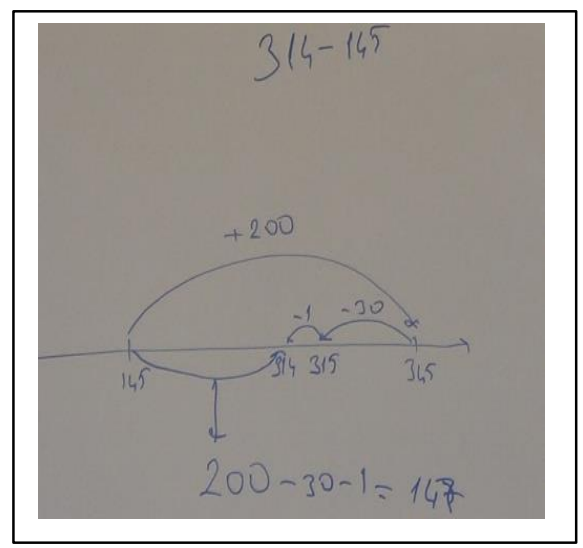

Şekil 6. Meltem'in çıkarma işleminin çözümü

Meltem'in yukarıdaki açıklamasında gerekçeyi vererek iddiada bulunduğu gözlemlenmiştir. Aslında öğretim elemanı aynı çözümü başka bir kişinin yapıp yapmadığını sorduğunda kimsenin Meltem'in çözümünün aynısını yapmadığını gözlemlemiştir. Fakat sınıf tarafından çözüm genel olarak anlaşıldığı için destekleyici bir ifade kullanılmasına gerek olmamıştır. Burada tartışma modeli kullanılarak Meltem'in iddiasını gerekçelendirebildiği ve matematiksel olarak nasıl düşündüğü gözlemlenmiştir. Açıkça görülmektedir ki tartışmada Meltem konuşmasının içeriğinin ilk kısmında kendi düşüncelerini ifade etmiş (author) daha sonra ise farklı kelimelerle söylediklerini tekrarlayarak (spokesman) iddiada bulunmuştur.

Meltem'in bireysel olarak verilen ödevdeki çıkarma sorusunda ise kutu ve çubukları nasıl kullandığı gözlemlenmiştir. Soruda öğrencilerden 425-167 sorusunu çözmeleri istenmiştir. Meltem çözümünde 4 kutu, 2 şerit ve 5 tane ile 425 sayısını göstermiştir. Daha sonra aynı ifadeyi 3 kutu, 11 şerit ve 15 tane ile ifade etmiş, 167 sayısını yani 1 kutu, 6 şerit ve 7 taneyi bu sayıdan çıkarmıştır. Sonuçta 2 kutu, 3 şerit ve 6 tane kalmıştır

\footnotetext{
${ }^{1}$ Bu İngilizce kelimelerin Türkçe karşılığı tam olarak anlamı vermediğinden aynen bırakılmıştır.
} 
(Şekil 7). Bu soruda Meltem kutuların 100 (bir-sıfır-sıfır)'ı, şeritlerin 10 (bir-sıfır)'ı ve tanelerin de 1'i temsil ettiğini belirtmiştir.

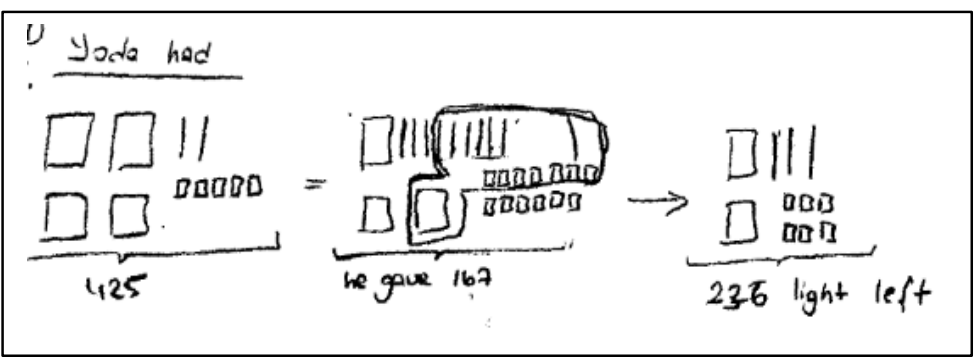

Şekil 7. Meltem'in şekilleri kullanan çözümü

Meltem'in kağıtta yazmış olduğu açıklama incelendiğinde, sorunun cevabında önce detaylı olarak gerekçeler ile veri' yi sunduğu daha sonra ise iddia da bulunduğu gözlemlenmiştir. Burada ifade edilmelidir ki Meltem kağıt üstünde kendi düşüncelerini ifade ederek author rolünde yer almıştır. Etkinlik kağıdında verilen sorular Meltem'in iddiasını gerekçelendirmesini desteklemiştir.

\section{Çarpma}

Toplama ve çıkarmadan sonra ertesi hafta çarpma işlemine geçilmiştir. Çarpma konusuna geçildiğinde öğrencilere "bir şeker fabrikasında makine her bir kutuya 17 şeker koyuyor, 6 kutudaki şekerin miktarını bulunuz" gibi sorular sorulmuştur. Daha sonra ise yumurta kutusu tasarlama ile ilgili sorular yöneltilmiştir. Örneğin, "6'ya 12'lik bir yumurta kutusuna kaç tane yumurta yerleştirilebilir?". Bu sorunun çözümünde Meltem öncelikle şekil çizmiş daha sonra yumurtaları gruplayarak çözümü bulmuştur (Şekil 8):

\section{Ö: Nasıl düşündün çözümü?}

M: Öncelikle her bir sırada 12 tane olacak şekilde 6 sıra var onu çizdim. Daha sonra her sıradaki 10'lukları grupladım. Geriye her sırada saymadığım 2 yumurta kaldı. Onları da 10'luğa tamamladım. En sonda ise 4 tane kaldı (veri).

Ö: Sonucu kaç buldun?

M: 6 tane alt alta onluğum 60 ediyor. Daha sonra da yandaki bir onluğu daha ekledim, en sonra da kalan 4'ü ekleyerek toplam 74 buldum (gerekçe ve iddia).

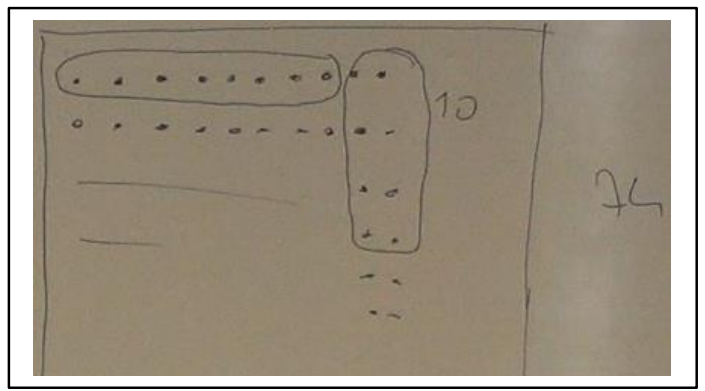

Şekil 8. Meltem'in çarpma sorusunun çözümü

Burada belirtilmesi gereken önemli bir nokta Meltem'in çözümünde bütün şekli çizmemesine rağmen öğrencilerin şekli kolaylıkla gözünde canlandırarak çözümü görselleştirebilmeleridir. Daha önceki şeker fabrikası sorularını çizerek imajlarının desteklenmesinin yumurta sorularının çözümünde öğrencilere çok faydalı olduğu görülmüştür. Yukarıdaki diyalogda Meltem yine sınıf ortamında iddiada bulunurken gerekçe ile açıklamasını yapmış fakat sınıf ortamında çözüm kolaylıkla anlaşıldığı için destekleyici ifadeye gerek kalmamıştır. Meltem konuşmasının başında author olarak tartışmaya veri sunarak başlamıştır. Daha sonra öğretim elemanı Meltem'i iddiasını sunmaya yöneltmek için sonucu tekrar etmesini istemiştir. Meltem sonucu 
ifade ederken farklı kelimelerle sonucu nasıl bulduğunu tekrar gerekçelendirerek (spokesman) cevabın 74 olduğunu iddia etmiştir.

Diğer bir çarpma sorusunda ise Meltem'in bireysel olarak yaptığı ödev sorusu incelenmiştir. Bu sorunun çözümünde ise Meltem'in alanı kullanarak çözüm yaptığı gözlemlenmiştir. Fakat çözüm sırasında Meltem'in sekizlik tabanı unutarak bazı kısımlarda onluk tabanda işlem yaptığı görülmüştür. Bu da öğrencilerin geçmiş deneyimlerinin çalışkan ve dikkatli olarak düşündüğümüz öğrencilerin çözümlerinde bile etkili olduğunu göstermektedir. Verilen ödev sorusunda Ali'nin her bir sinema biletinden 13 TL kazandığı ve 15 bilet satarsa toplamda kaç TL kazanacağı sorulmuştur. Meltem'in çözümü aşağıdaki gibidir:

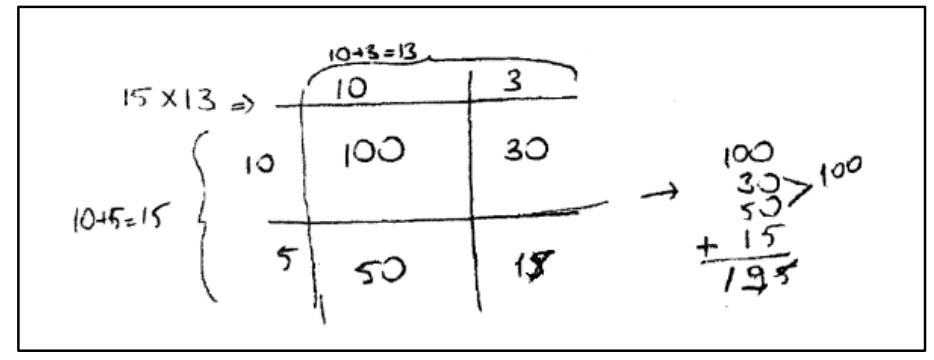

Şekil 9. . Meltem'in alanı kullanarak çözümü

Şekilde de görüldüğü gibi Meltem ilk önce 13'ü 10 ve 3 olarak, 15'i de 10 ve 5 olarak düşünmüştür. Fakat çarpma işlemi sırasında 5 ve 3'ü çarparken onluk tabanda gibi düşünüp 17 yerine 15 yazmıştır (Şekil 9). Bu kısımda Meltem yine veriyi gerekçesi ile birlikte yazılı olarak açıklamış ve daha sonra sorunun sonucunu vermek içim iddiada bulunmuştur. Etkinlikte yer alan problemlerin çözümünde öğretim elemanı sorularla öğrencilerin matematiksel düşünmesini gerekçelendirmelerini desteklemiştir.

\section{Bölme}

Son olarak ise sekizlik tabanda bölme işlemi yapılmıştır (Şekil 10). Aşağıda verilen diyalogda Meltem şu soruyu çözmüştür "Mert'in 236 etiketi vardır ve bunu her arkadaşına 14 tane gelecek şekilde eşit paylaştırmak istemektedir. Bunun için Mert kaç arkadaşına etiketi paylaştırabilir ve kaç tanesi Mert'e kalır?"

\section{Ö: Nasıl çözdün soruyu?}

M: 6'nın içinde 14 yok zaten, 30'un içinde 2 tane var. 200'in içinde kaç tane var ona baklyorum. 14 ile 10'u çarparsam 140 oluyor. Daha 200'e gelmeme var. Sonra 30 daha ekliyorum 170 ediyor (gerekçe).

Başka bir öğrenci: Meltem tekrar baştan anlatabilir misin?

M: ilk önce basamaklara ayırdım. 6'da 14 yok, 30 da 2 tane var, 170 de de $14 \times 12$ tane var (gerekçe).

Ö: 170'dekini tahmin mi ediyorsun?

M: Evet. 200'den 170'i çıkardığım zaman burada 10 kalıyor. Diğer tarafta da 6 vardı. Toplamda 16 oldu. 16'nın içinde de 1 tane var.

B.Ö: Ben anlamadım.

M: Nereden sonrasını anlamadın? Baştan mı anlatıyım?

B.Ö: 170'den sonrasını

M: 170'in içinde 12 tane var. 200'e gelmeye 10 kaldı 6 ile birleştirirsek oradan da 1 tane gelir. 30'da da 2 tane vardı, toplamda 12+2+1=15 tane oluyor ve 16'dan da 2 tane artar (iddia).

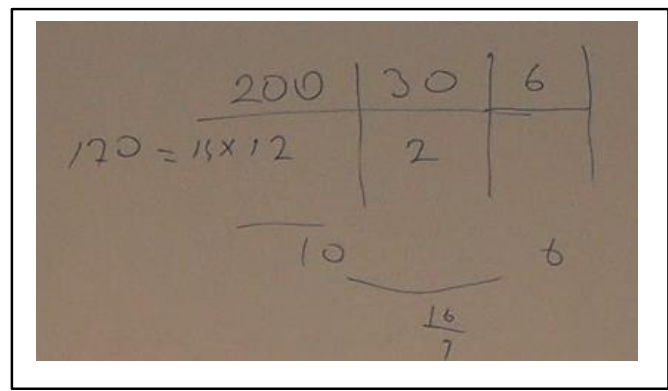


Bölme sorusunu açıklarken Meltem her zaman olduğu gibi iddiasını gerekçe ile açıklamasına rağmen bölme işlemini öğrenciler işlemsel yapmaya alıştıklarından Meltem'in iddiası birçok öğrenci tarafından anlaşılamamıştır. Bu nedenle Meltem başta sunduğu iddiasını farklı sözlerle ifade ederek tekrarlamıştır (spokesman). Bu iddiasının gerekçesi olarak da öncelikle 236'nın içinde kaç tane 14'lük var sorusunun cevabını tahmin etmeye çalıştığını ifade etmiştir. Bunun için öncelikle tahmini olarak 10 sayısını verdiğini daha sonra elindeki etiketin fazla kaldığını ve onu da 6 kişiye daha paylaştırabileceğini sonunda da 2 etiketin arttığını detaylı olarak açıklayarak belirtmiştir.

Meltem bireysel yaptığı bölme sorusunun çözümünde yine sekizlik tabanı onluk taban gibi düşünerek işlem hatası yapmıştır. Sınavda verilen soru şu şekildedir: "Can'ın 533 kalemi vardır ve her bir arkadaşına 27 kalem vermek istemektedir. Kaç tane arkadaşına verebilir ve kaç tane geriye kalır?". Aşağıda Meltem'in çözümü verilmektedir (Şekil 11). Meltem öncelikle 27 ile 20'ı çarparak 560'ı bulmuştur. Sonra eğer 27 çıkarırsa 531 kalem kalacağını belirtmiştir. Buradan kalemleri 20-1 yani 19 kişiye verebileceğini ve 2 kalemin de artacağını ifade etmiştir. Burada aslında 19 yerine 17 denmesi gerekmektedir fakat geçmişteki deneyimlerinin de etkisiyle soruyu onluk tabanda çözmüştür.

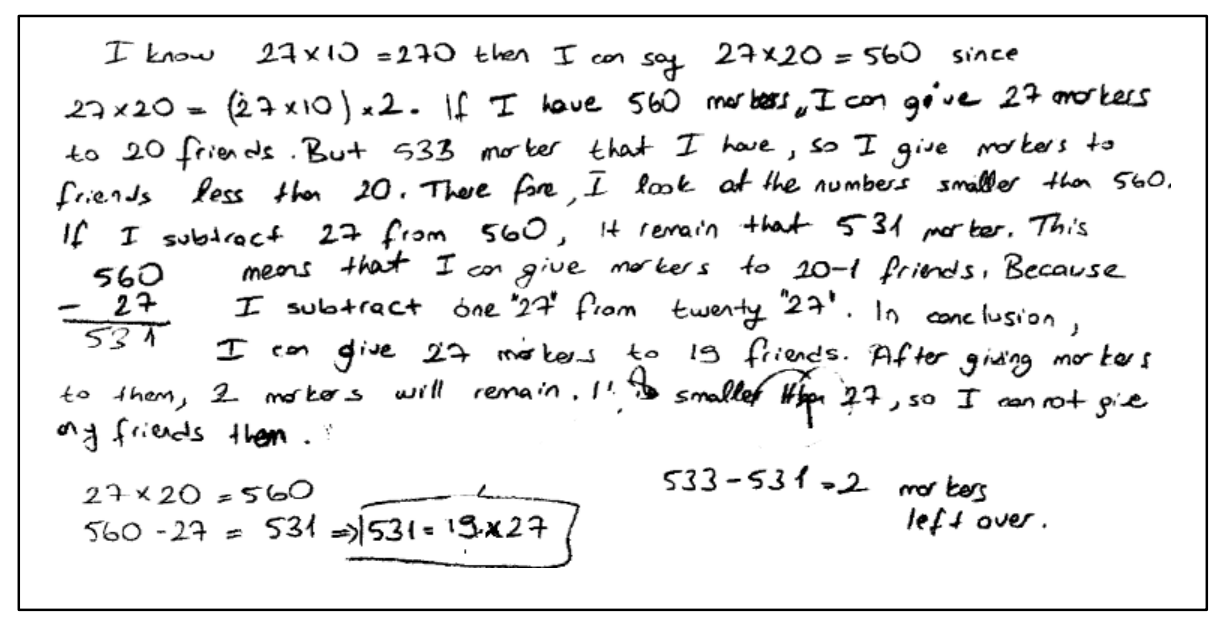

Şekil 11. Meltem'in bölme sorusundaki çözümü

Meltem yine yazılı olarak sadece sorunun cevabını iddia etmemiş bu cevabı aynı zamanda gerekçelendirmiştir. Bu da Meltem'in bölme konusunu nasıl düşündüğünü anlamamız konusunda önemli olmuştur.

Yapılan çözümlerde Meltem'in doğal sayılardaki farklı işlemlerde sorulan soruları artık otomatikleşmiş olan yöntemler yerine düşünerek ve soruları anlamlandırarak çözdüğü gözlemlenmiştir. Bu çözümlerin bulunmasında sekizlik taban kullanmanın önemi büyüktür. Aksi halde öğrencilerin birçoğu doğal sayılar konusundaki bu işlemleri zihinden kolaylıkla yapabilir ve onların düşünmelerine çok da fazla fırsat verilmemiş olur.

\section{TARTIŞMA, SONUÇ VE ÖNERILER}

Bu çalışmada amaç öğretmen adaylarına benzer bir ortam sağlayarak onların doğal sayılar konusunu ve doğal sayılardaki işlemleri kavramsal olarak nasıl anladığını araştırmaktır. Bu doğrultuda öncelikle sorgulama tabanlı bir sınıf ortamı oluşturulmuş daha sonra ise Krummheuer (2015) tartışma modeli ile öğretmen adayının bu ortamda nasıl düşündükleri analiz edilmiştir. Yapılan çalışmalar sorgulama tabanlı ortamın öğretmen adaylarının matematiksel anlayışını geliştirdiğini göstermektedir (Kazemi \& Franke, 2004). Böyle bir ortamda öğretmen adaylarının anlamalarının nasıl geliştiğini analiz etmek için gelişen perspektif teorik çerçeve olarak kullanılmıştır (Cobb \& Yackel, 1996). Bu perspektife göre öğrenciler hem sosyal hem de bireysel olarak matematiği öğrenirler. Bu nedenle de çalışmada detaylı olarak öğretmen adayının sınıf ortamındaki çözümlerinin yanı sıra bireysel olarak çözmüş olduğu ödev ve sınavları da incelenmiştir. 
Bu çalışmada bir matematik öğretmen adayının yapmış olduğu çözüm stratejileri sunulmuştur. Yöntem kısmında da belirtildiği gibi bu öğretmen adayı başarılı bir öğrencidir. Maalesef diğer matematik öğretmen adayları bu çalışmada incelenen öğretmen adayı gibi farklı çözümler getirememiş, hatta birçok sorunun çözümünde sıkıntılar yaşamışlardır. Alanyazını incelediğimizde öğretmen adaylarının doğal sayıları nasıl öğrettiği ile ilgili araştırmalar göz önüne alındığında bu çalışmaların çoğunun sınıf öğretmenleri üzerinde olduğu gözlemlenmektedir. Bu çalışmalar da öğretmen adaylarının doğal sayılar ve doğal sayılardaki işlemlerin anlamlarını yorumlamakta ve öğrenci hatalarını tahmin etmede yeterli bilgiye sahip olmadığını göstermektedir (Ball, 1990; Son \& Crespo, 2009; Son \& Sinclair, 2010). Çoğu zaman öğretmen adayları hatanın neden kaynaklandığını açıklamak yerine sonucu düzeltmeye yönelmiştir. Bu nedenle bu çalışmada kullanılan içeriğin hem matematik hem de sınıf öğretmen adaylarının alan bilgisini geliştirmek için kullanılabileceği düşünülmektedir.

Çalışmada öğretmen adayının düşüncelerini doğal bir ortamda incelemek amacıyla geçmişte onluk tabanla çok fazla deneyimleri oldukları için sekizlik taban kullanılması tercih edilmiştir. Böylece öğretmen adaylarına öğrencilerin bakış açısıyla doğal sayıları keşfetmelerine olanak sağlayacak bir ortam sunulmuştur. Gerçekten çalışmada incelenen öğretmen adayının çözümleri daha önceden öğrencilerle onluk tabanda doğal sayılar ile yapılan çalışmalardaki öğrenci çözümleri ile karşılaştırıldığında büyük benzerlikler göstermektedir (Huinker, Freckman \& Steinmeyer, 2003; Selter, 2002). Bu da doğal sayılar da işlemlerin öğretiminde sekizlik taban ya da farklı bir taban kullanmanın öğretmen adaylarının düşünce şeklini değiştirdiğini, ezberden çıkarak farklı bir bakış açısıyla soruları yorumladıklarını göstermektedir.

Bu çalışmanın önemli sonuçlarından biri de açık sayı doğrusunun öğretmen adaylarının çözüm stratejileri geliştirmede kullanabilecekleri önemli bir araç olduğunun gözlemlenmiş olmasıdır. Açık sayı doğrusu ile ifade edilmek istenen üzerinde hiç bir rakamın ve işaretin bulunmadığı sayı doğrusudur. Açık sayı doğrusu öğrencilerin dört işlem yaparken matematiksel düşünmelerini ve farklı stratejileri kullanmalarını desteklemek için sadece doğal sayılar konusunda değil kesirler konusunda da bir çok araştırmacı tarafından kullanılmıştır (Izsak, Tillema \& Tunc-Pekkan, 2008; Kennedy, 2000; Klein, Beishuizen \& Treffers, 1998, Selter, 1998). Bu çalışmada da açık sayı doğrusu öğretmen adaylarının matematiksel düşüncelerini desteklemek ve onlara problem çözümlerinde kullanabilecekleri bir araç olarak tanıtılmıştır.

Çalışmada Meltem'in sınıf tartışmaları sırasında tamsayı problemlerinin çözümlerinde değişik stratejiler geliştirdiği gözlemlenmiş ve farklı kavramları birbirine bağlayarak diğer öğretmen adaylarının da kavramsal anlamalarına katkıda bulunduğu fark edilmiştir. Örneğin, kullanmış olduğu açık sayı doğrusu ve bu sayı doğrusunda yapmış olduğu çözüm ve gruplama stratejileri diğer öğretmen adaylarını da farklı çözümler bulmaya teşvik etmiştir. Bunun yanı sıra Meltem yapmış olduğu çözümlerde konular arasında bağlantı kurmaya çalışmış ve sınıfta arkadaşları tarafından sunulan çözümleri de anlamak için çaba sarf etmiştir. Meltem'in farklı stratejiler kullanmasına rağmen, bazı problemlerin çözümünde sekizlik tabanı unutarak onluk tabanda işlem yaptığı görülmüştür. Bunu önlemek için daha önceden de belirtildiği gibi 10 ve 100 onluk sistemlerindeki isimleri ile değil bir-sıfır ve bir-sıfır-sıfır olarak isimlendirilmiştir. Fakat yine de bu adlandırmalar öğrencilerin zorluk yaşamalarına sebep olmuş olabilir. Çünkü onluk sistemde bu sayılar onluk ve yüzlük diye tekrardan isimlendirilmiştir. Delil (2014) eğer elimizin parmaklarından esinlenerek beşlik tabanda sayma yapsaydık; beş-beşliklere özel bir isim olarak yeşlik, beş-beş-beşliklere keşlik vb isimlere verebileceğimizi ifade etmektedir. Bu araştırmada kullanılan içeriği uygulamak isteyen çalışmalar 10'ı sekizlik; 100'ı sekizsekizlik diye okuyup bunlara özel olarak da farklı isimler verebilirler (ör. mekizlik, kekizlik).

Daha önceki çalışmalar gibi bu çalışmada da tamsayılarda işlemler konusunda öğretmen adaylarının derinlemesine bilgili olmasının doğal sayılardaki işlemleri yaparken nasıl ve niye olduğunu açıklamak gerektiğinden geçtiği gösterilmektedir (Hill \& Ball, 2004; Son, 2016a, 2016b). Bu çalışmada sunulan farklı yolların öğretmen adaylarının doğal sayılar ile ilgili bilgilerini desteklemede kullanılabileceği düşünülmektedir.

Çalışmada kullanılan sekizlik taban eğitimciler tarafından kullanılarak, hem matematik hem de sınıf öğretmeni adaylarının doğal sayılarda işlemleri daha iyi anlamalarına yardımcı olabilir. Bunun yanı sıra sınıfta kullanılan çözüm stratejileri arasından Meltem'in çözümlerine benzeyen değişik stratejiler geliştirilemez ise öğretim elemanı farklı stratejilerden örnekler vererek doğal sayıları kavramsal olarak anlamayı destekleyebilir. Özellikle, açık sayı doğrusunu kullanarak yapılan farklı çözümler; toplama ve çıkarmadaki gruplama mantığının anlaşılmasında yardımcı olabilecek şeker kutulama içeriği ve çarpmada kullanılabilecek farklı sayılarda bölmeleri olan yumurta kaplarındaki yumurta sayılarını hesaplama durumları öğretmen adaylarının doğal sayılarda işlemlerin içeriğini daha iyi anlamalarına yardımcı olacaktır. Öğretmen adaylarının sayı hissinin yeterince gelişmediği ve bir çok öğretmen adayının doğal sayılardaki işlemleri sadece algoritmaya bağlı kalarak çözdüğü düşünüldüğünde, böyle bir içeriğin öğretmen adaylarının doğal sayıları yeniden keşfetmeleri için önemli olduğu görülmektedir (Tasao, 2005; Yang, 2007). Burada tekrar hatırlatılması gereken en önemli nokta öğretmen adaylarının doğal sayılar konusundaki problemleri çözerken artık hiç düşünmeden işlem 
yaptıkları onluk taban yerine başka bir tabanın kullanılması gerektiğidir. Eğer öğrencilerimizin doğal sayılar konusunu ve doğal sayılar üzerindeki işlemleri iyi anlamalarını istiyorsak geleceğin öğretmenleri olan öğretmen adaylarını bu konuda geliştirmek ve desteklemek öğretim elemanlarının önemli bir sorumluluğudur.

\section{KAYNAKÇA/REFERENCES}

Andreasen, J. B. (2006). Classroom mathematical practices in a preservice elementary mathematics education course using an instructional sequence related to place value and operations. Unpublished Doctoral Dissertation, University of Central Florida.

Ashlock, R. B. (2002). Error patterns in computation: Using error patterns to improve instruction (8th ed.). Upper Saddle River, NJ: Merrill Prentice Hall.

Ball, D. L. (1990). The mathematical understandings that prospective teachers bring to teacher education. The Elementary School Journal, 90, 449-466.

Ball, D. \& Hill, H. (2008). Study of instructional improvement/learning mathematics for teaching. http://www.umich.edu/ Imtweb/files/lmt_sample_items.pdf adresinden elde edinilmiştir.

Ball, D., Bass, H., \& Hill, H. (2004). Knowing and using mathematical knowledge in teaching: Learning what matters. In Proceedings for the 12th Annual Conference of the South African Association for Research in Mathematics, Science and Technology Education. Durban. SAARMSTE.

Cady, J. A., Hopkins, T. M., \& Hodges, T. E. (2008). Lesson study as professional development for mathematics teacher educators. Inquiry into Mathematics Teacher Educati, 119.

Creswell, J. W. (1998). Qualitative inquiry and research design: Choosing among five traditions. Thousand Oaks, CA: Sage Publications.

Cobb, P. \& Wheatley, G. (1988). Children's initial understandings of ten. Focus on Learning Problems in Mathematics, 10 (3), 1-28.

Cobb, P. (2001). Supporting the improvement of learning and teaching in social and institutional context. Cognition and instruction: Twenty-five years of progress, 78.

Cobb, P., \& Yackel, E. (1996). Constructivist, emergent, and sociocultural perspectives in the context of developmental research. Educational psychologist, 31(3-4), 175-190.

Denzin, N. K., \& Lincoln, Y. S. (2000). Handbook of qualitative research (2nd ed.). Thousand Oaks, CA: Sage Publications.

Delil, A. (2014). Sayılar. Kaçar, A (Ed.). Temel Matematik I-II. (ss. 21-61). Pegem Akademi, Ankara.

Empson, S. B., \& Junk, D. L. (2004). Teachers' knowledge of children's mathematics after implementing a student-centered curriculum. Journal of Mathematics Teacher Education, 7(2), 121-144.

Hiebert, J., \& Grouws, D. A. (2007). The effects of classroom mathematics teaching on students' learning. Second handbook of research on mathematics teaching and learning, 1, 371-404.

Hill, H. C., \& Ball, D. L. (2004). Learning mathematics for teaching: Results from California's Mathematics Professional Development Institutes. Journal of Research in Mathematics Education, 35, 330-351.

Hill, H. C., Ball, D. L., \& Schilling, S. G. (2008). Unpacking pedagogical content knowledge: Conceptualizing and measuring teachers' topic-specific knowledge of students. Journal for Research in Mathematics Education, 39(4), 372-400.

Hopkins, T. M., \& Cady, J. A. (2007). What is the value of@*\#. Teaching Children Mathematics, 13(8), 434-437.

Huinker, D., Freckman, J. L., \& Steinmeyer, M. B. (2003). Subtraction strategies from children's thinking: Moving toward fluency with greater numbers. Teaching Children Mathematics, 9, 347-353.

Izsak, A., Tillema, E., \& Tunc-Pekkan, Z. (2008). Teaching and learning fraction addition on number lines. Journal for Research in Mathematics Education, 39(1), 33-62.

Kazemi, E., \& Franke, M. L. (2004). Teacher learning in mathematics: Using student work to promote collective inquiry. Journal of Mathematics Teacher Education, 7(3), 203-235.

Kennedy, P. A. (2000). Concrete representation and number line models: connecting and extending. Journal of Developmental Education, 24(2), 2-8.

Kilpatrick, J., Swafford, J., \& Findell, B. (Eds.) (2001). Adding it up: Helping children learn mathematics. Washington, D.C.: National Academy Press.

Klein, A. S., Beishuizen, M., \& Treffers, A. (1998). The empty number line in Dutch second grades: realistic versus gradual program design. Journal for Research in Mathematics Education, 29, 443-464.

Krummheuer, G. (1995). The ethnography of argumentation. Lawrence Erlbaum Associates, Inc.

Krummheuer, G. (2007). Argumentation and participation in the primary mathematics classroom: Two episodes and related theoretical abductions. The Journal of Mathematical Behavior, 26(1), 60-82. 
Krummheuer, G. (2015). Methods for Reconstructing Processes of Argumentation and Participation in Primary Mathematics Classroom Interaction. In Bikner-Ahsbahs, A. Knipping, C. Presmeg, N. C. (Eds.), Approaches to Qualitative Research in Mathematics Education. (pp. 51-75). Springer Netherlands.

Lerman, S. (2000). A case of interpretations of social: A response to Steffe and Thompson. Journal for Research in Mathematics Education, 31(2), 210-227.

Markovits, Z., \& Sowder, J. (1994). Developing number sense: An intervention study in grade 7. Journal for Research in Mathematics Education, 25, 4-29.

Maxwell, J. A. (1996). Qualitative research design: An interactive approach. Applied social research methods series, v. 41. Thousand Oaks, CA: Sage Publications.

McClain, K. (2003). Supporting preservice teachers' understanding of place value and multidigit arithmetic. Mathematical Thinking and Learning, 5(4), 281-306.

McIntosh, A., Reys, B. J., \& Reys, R. E. (1992). A proposed framework for examining basic number sense. For the learning of mathematics, 12(3), 2-44.

MEB (2015). Illkokul Matematik Dersi (1, 2, 3 ve 4. Sınıflar) Öğretim Programı. T.C. Milli Eğitim Bakanlığı. Talim ve Terbiye Kurulu Başkanlı̆̆ı, Ankara.

Menon, R. (2004). Preservice teachers' number sense. Focus on Learning Problems in Mathematics, 26(2), 4961.

Merriam, S. B. (1988). Case study research in education: A qualitative approach (1st ed.). San Francisco, CA: Jossey-Bass.

Philipp, R. A., Ambrose, R., Lamb, L.L.C., Sowder, J. T., Schappelle, B. P., Sowder, L., Chauvot, J. (2007). Effects of early field experiences on the mathematical content knowledge and beliefs of prospective elementary school teachers: An experimental study. Journal for Research in Mathematics Education, 38, 438-476

Ross, S. H. (2001). Pre-service elementary teachers and place value: Written assessment using a digitcorrespondence task. In C. N. Walter (Ed.), Proceedings of the twenty-third annual meeting of the north American chapter of the International Group for thePpsychology of Mathematics Education (pp. 897906) Snowbird, UT: ERIC Clearinghouse for Science, Mathematics, and Environmental Education.

Roy, G. (2008). Prospective Teachers' Development Of Whole Number Concepts And Operatıons Durıng A Classroom Teachıng Experıment. Unpublished Doctoral Dissertation, University of Central Florida.

Safi, F. (2009). Explorıng The Understandıng Of Whole Number Concepts And Operatıons: A Case Study Analysıs Of Prospective Elementary School Teachers. Unpublished Doctoral Dissertation, University of Central Florida.

Selter, C. (1998). Building on children's mathematics: a teaching experiment in grade three. Educational Studies in Mathematics, 36(1), 1-27.

Selter, C. (2001). Addition and subtraction of three-digit numbers: German elementary children's success, methods and strategies. Educational Studies in Mathematics, 47(2), 145-173.

Shumway, J. F. (2011). Number sense routines: Building numerical literacy every day in grades $K$-3. Stenhouse Publishers.

Son, J., \& Crespo, S. (2009). Prospective teachers' reasoning about students' non-traditional strategies when dividing fractions. Journal of Mathematics Teacher Education, 12(4), 236-261.

Son, J., \& Sinclair, N. (2010). How preservice teachers interpret and respond to student geometric errors. School Science and Mathematics, 110(1), 31-46.

Son, J. W. (2016a). Moving beyond a traditional algorithm in whole number subtraction: Preservice teachers' responses to a student's invented strategy. Educational Studies in Mathematics, 1-25. doi: 10.1007/s10649-016-9693-8.

Son, J. W. (2016b). Preservice teachers' response and feedback type to correct and incorrect student-invented strategies for subtracting whole numbers. The Journal of Mathematical Behavior, 42, 49-68.

Stake, R. E. (2006). Multiple case study analysis. New York, NY: The Guilford Press.

Stephan, M., \& Akyuz, D. (2012). A proposed instructional theory for integer addition and subtraction. Journal for Research in Mathematics Education, 43(4), 428-464.

Thanheiser, E. (2009). Preservice elementary school teachers' conceptions of multidigit whole numbers. Journal for Research in Mathematics Education, 40(3), 251-281.

Thanheiser, E. (2010). Investigating further preservice teachers' conceptions of multidigit whole numbers: Refining a framework. Educational Studies in Mathematics, 75(3), 241-251.

Tirosh, D. (2000). Enhancing prospective teachers' knowledge of children's conceptions: The case of division of fractions. Journal for Research in Mathematics Education, 5-25.

Toulmin, S. E. (1969). The uses of argument. Cambridge, The University Press. 
Tsao, Y.L. (2004 ). Effects of a problem-solving-based mathematics course on number sense of pre-service Teachers. Journal of College Teaching \& Learning, 1(2),33-49.

Tsao, Y .L. (2005). The number sense of pre-service elementary teachers. College Student Journal, 39(4), 647679.

Uçar, Z. T. (2011). Öğretmen adaylarının pedagojik içerik bilgisi: öğretimsel açıklamalar. Turkish Journal of Computer and Mathematics Education, 2(2), 87-102.

Yang, D. C. (2007). Investigating the strategies used by pre-service teachers in Taiwan when responding to number sense questions. School Science and Mathematics, 107(7). 293-301.

Yang, D. C., \& Huang, F. Y. (2004). Relationships among computational performance, pictorial representation, symbolic representation and number sense of sixth- grade students in Taiwan. Educational Studies, 30(4), 373-389

Yin, R. K. (2003). Applications of case study research (2nd ed.). Thousand Oaks, CA: Sage Publications.

Zazkis, R., \& Khoury, H. A. (1993). Place value and rational number representations: Problem solving in the unfamiliar domain of non-decimals. Focus on Learning Problems in Mathematics, 15(1), 38-51.

İletișim/Correspondence

Doç. Dr. Didem Akyüz dakyuz@metu.edu.tr 